\title{
Valores em serviços de policiamento comunitário: o Programa Ronda do Quarteirão sob a ótica da teoria da cadeia de meios e fins
}

\author{
Liliane Araújo Pinto \\ Instituto Federal do Piauí \\ Luiz Carlos Murakami \\ Universidade Federal do Ceará \\ Márcio Lopes Pimenta \\ Universidade Federal de Uberlândia \\ Natália de Sena Nunes \\ Universidade Federal do Ceará
}

\begin{abstract}
O crescimento da violência, a preocupação mais intensa dos cidadãos pela busca da segurança e as estratégias gerenciais adotadas por organizações privadas contribuíram para que as organizações policiais adotassem um novo modelo de policiamento - "o policiamento comunitário", com foco na parceria entre a sociedade e a polícia para juntos melhorarem a sensação de bem-estar das pessoas. Este artigo tem como objetivo analisar, sob a ótica da teoria da cadeia de meios e fins, a estrutura de valores dos usuários dos serviços de policiamento comunitário: o Ronda do Quarteirão na cidade de Fortaleza (CE), tomando como base a identificação de atributos do serviço percebidos por estes usuários e das relações entre os atributos e suas consequências na utilização do serviço com os valores pessoais dos indivíduos. Utilizou-se a técnica de laddering que permite a construção do mapa hierárquico de valor, evidenciando os elementos que caracterizam o comportamento dos consumidores ao utilizarem tal serviço. Os resultados mostram a preocupação dos usuários dos seviços do Ronda do Quarteirão em atingir o bem-estar que poderá ser adquirido na realização dos valores: amar o que faz, amizade, cidadania, defender a pátria, felicidade, honestidade, satisfação, segurança e sentir-se útil à sociedade.
\end{abstract}

Palavras-chave: comportamento do consumidor; policiamento comunitário; valores; cadeia de meios e fins; laddering.

Values in communitarian police services: the Block Patrol Program under the means end-chain theory view

The increase of violence, the more intense citizen's search for security contributed for a new model of police offered by government which is the "community police". This kind of police is developed in

Artigo recebido em ago. 2010 e aceito em jul. 2011. 
many countries in order to create a close relationship with the society. It is focused on the partnership between society and police to develop jointly an improved people's welfare. This paper's objective is to make an analysis, under the means end-chain theory, of the values structure of the users of "Block patrol" a community police created in a capital city of the northeast of Brazil. First, this study identifies the main attributes of the services as attendance speed, nice clothing, credibility. The second step was to relate these attributes to the consequences to the user. These main attributes perceived by these users and the relation between these and its consequences lead to the values. The laddering technique was used which allowed the construction of the hierarchical value map showing the user's behavior after the service experience. This map shows the main relationship with the attributes, consequences and values, allowing insights to an effective communication strategy. The values identified were: love, friendship, citizenship, happiness, honesty and satisfaction.

KEY WORDs: consumer's behavior; communitarian police; values; theory means end-chain; laddering.

\section{Introdução}

Diante dos novos padrões de violência urbana que emergiam no final da década de 1960 até meados da década de 1970, os países desenvolvidos (Austrália, Estados Unidos, Canadá, Japão, Noruega, Suécia, Dinamarca, Espanha, Finlândia, Cingapura) perceberam que o modelo de policiamento tradicional não atendia mais às necessidades dos cidadãos, pois a população encontrava-se desacreditada com o desempenho da polícia no combate à criminalidade (Senasp, 2007).

Percebeu-se, então, que as práticas e políticas adotadas pelas organizações privadas têm servido, nas últimas décadas, de exemplo para as instituições policiais. O modelo adotado pelas empresas particulares, que busca entender e satisfazer as necessidades dos clientes, está pautado no entendimento dos valores essenciais para esses clientes. O que tem mostrado resultados satisfatórios tanto para as organizações públicas como para os usuários destes produtos/serviços. No entanto as estratégias de segurança pública que funcionaram no passado deixaram de ser eficazes na atualidade. A polícia reconheceu que seu principal cliente (a sociedade) estava insatisfeito com a segurança ofertada pelo Estado.

Diante deste cenário, vem se tornando mais frequente a adoção de um policiamento mais "humanizado", um policiamento em relação ao qual a população deixou de ser agente passivo e tornou-se agente ativo no processo de construção de um mundo de paz.

No Brasil, várias tentativas de policiamento comunitário foram introduzidas nos últimos 18 anos, mas o presente estudo tem como foco o modelo adotado pelo estado do Ceará, que teve início no final do ano de 2007 - O Programa Ronda do Quarteirão. Tem-se como desafio detectar quais valores são predominantes na percepção dos usuários dos serviços do Ronda do Quarteirão. Desta forma, pretende-se construir o hierarquical value map (HVM), a fim de revelar os atributos, consequências e valores percebidos por estes usuários.

Segundo Pimenta (2008:13), “os valores são representações de estados desejados na vida do indivíduo movido por crenças e pressupostos individuais e coletivos." Adota-se o 
modelo de Schwartz (1992) como base de análise dos valores percebidos pelos usuários dos serviços de segurança pública em relação ao Programa Ronda do Quarteirão. Para construção do mapa hierárquico de valor, a estrutura teórica se baseia na teoria da cadeia de meios e fins idealizada por Gutman (1982), em conjunto com a técnica de laddering, bastante recomendada em pesquisas que abordam a ligação entre os valores pessoais de consumidores, ou usuários serviços, e respectivos atributos percebidos (Reynolds e Gutman, 1988).

A seguir, o artigo apresenta, como referencial teórico, um breve histórico e a conceituação do policiamento comunitário e o Programa Ronda do Quarteirão. Posteriormente, valores pessoais e cadeia de meios e fins. Os próximos capítulos seguem com a metodologia, análise e discussão dos resultados e considerações finais.

\section{Policiamento comunitário - o Programa Ronda do Quarteirão}

As insatisfações com os sistemas tradicionais de segurança pública - eminentemente repressivos - têm mexido com a maioria da população, o que faz aumentar a discussão sobre a metodologia de atuação da polícia junto à comunidade.

Muitos pesquisadores dos departamentos policiais, diante dessas insatisfações, começaram a pensar sobre programa de policiamento comunitário, do qual a sociedade devesse participar ativamente em prol de sua própria segurança, especialmente na elaboração de táticas preventivas (Jucá, 2002).

Segundo a Secretaria Nacional de Segurança Pública (Senasp, 2007), as estratégias de policiamento ou de prestação de serviço que funcionaram no passado não são mais eficazes, visto que a meta de aumentar a sensação de segurança e bem-estar não foi alcançada. "O nosso cliente (a sociedade, precisamente os cidadãos) está mais exigente, pois estamos em processo de contínua transformação" (Senasp, 2007:119).

Com essa inquietação, o policiamento comunitário tem-se mostrado como a grande possibilidade de ampliar essa discussão. Tendo se expandido em diversos países nas décadas de 1970 e 1980, cada país adotou características próprias e diferenciadoras, mas todas as experiências tiveram um aspecto em comum: a introdução ou o fortalecimento da participação da comunidade nas questões de segurança (NEV/USP, 2009).

\subsection{Conceitos de policiamento comunitário}

As recentes mudanças na área policial demonstram que a eficácia de uma política de prevenção do crime e produção de segurança está diretamente ligada à construção de uma relação sólida e positiva entre polícia e sociedade (Brown, 1988, apud Dias Neto, 2003).

Segundo Skolnick e Bayley (2006:57) "o policiamento comunitário cresceu a partir da concepção de que a polícia poderia responder de modo sensível e apropriado aos cidadãos e às comunidades". 
Dias Neto (2003:30) ressalta que "o policiamento comunitário expressa uma filosofia operacional orientada à divisão de responsabilidades entre polícia e cidadãos no planejamento e na implementação das políticas públicas de segurança".

De acordo com Trojanowicz e Bucqueroux (1994:4-5),

polícia comunitária é uma filosofia e uma estratégia organizacional que proporciona uma nova parceria entre a população e a polícia. Baseia-se na premissa de que tanto a polícia quanto a comunidade devem trabalhar juntas para identificar, priorizar e resolver problemas contemporâneos tais como crimes, drogas, insegurança, desordens físicas e morais e em geral a decadência do bairro, com o objetivo de melhorar a qualidade de vida local [...].

Conforme observado, a definição de policiamento comunitário está ligada à aproximação dos profissionais de segurança pública da comunidade onde atuam. Neste contexto, observa-se que a organização policial precisa saber o que é importante para as pessoas, quais valores são essenciais a elas para traçar estratégias eficazes.

\subsection{O Programa de Policiamento Comunitário - Ronda do Quarteirão}

Com uma concepção de polícia ostensiva diferente da polícia tradicional, o Ronda do Quarteirão iniciou suas atividades, como projeto piloto, no final de 2007, em alguns bairros da capital cearense e em parte do município de Maracanaú, como proposta do Governo do Estado do Ceará, nessa época sob o comando de Cid Gomes. O projeto adotou o slogan "Polícia da Boa Vizinhança", atendendo à comunidade, 24 horas por dia, de maneira ostensiva e preventiva, trabalhando pela manutenção da paz e da ordem pública.

Em 2008, o Ronda do Quarteirão já atuava em toda a cidade de Fortaleza, em Caucaia e Maracanaú, contando com um quadro efetivo de 1.494 soldados e 151 viaturas. Em setembro de 2009, o programa foi ampliado para atender 24 municípios cearenses, contando com 2.408 policiais, atuando 24 horas por dia, com 212 viaturas da marca Toyota, modelo Hi-lux, e 205 motos Honda, modelo Falcon 450 cilindradas (Secretaria de Segurança Pública e Defesa Social, 2009).

Cada viatura policial é responsável por uma área que mede de 1,5 a $3 \mathrm{~km}^{2}$ de extensão, no máximo. Cada uma dessas áreas é patrulhada por uma equipe de oito a 12 policiais especialmente treinados, que revezam em três turnos de oito horas por dia.

Após seis meses de implantação do Programa Ronda do Quarteirão, o jornal O Povo/ Datafolha realizou em 2008 pesquisa com 816 pessoas com faixa etária acima de 16 anos de idade, para medir o grau de satisfação da população em relação ao programa. A pesquisa revelou que $72 \%$ dos entrevistados consideram o progama Ronda do Quarteirão como ótimo/bom e apenas 5\% avaliaram-no como ruim/péssimo. Segundo a pesquisa, 66\% dos entrevistados afirmaram sentir-se mais seguros após a implantação do Ronda do Quarteirão (Ronda, 2008). 
Studart (2009) realizou uma comparação entre os dois momentos: antes do ronda do quarteirão e depois do ronda do quarteirão, para avaliar as mudanças obtidas, conforme quadro 1.

Quadro 1

\section{Antes do Ronda e depois do Ronda do Quarteirão}

\begin{tabular}{|c|c|}
\hline Antes do Ronda & Depois do Ronda \\
\hline O foco da polícia estava no combate à criminalidade; & Criação da Cultura Ronda; \\
\hline $\begin{array}{l}\text { Abordagem reativa (após o fato delituoso) esperava algo acon- } \\
\text { tecer (crime) para depois reagir (às vezes tarde demais); }\end{array}$ & $\begin{array}{l}\text { Capacitação dos policiais como promotores da doutrina de } \\
\text { polícia comunitária e dos princípios dos direitos humanos; }\end{array}$ \\
\hline $\begin{array}{l}\text { Trabalhava na repressão dos 2\% da população (inclinada à } \\
\text { conduta criminosa); }\end{array}$ & Polícia da Boa Vizinhança; \\
\hline $\begin{array}{l}\text { A visão da Polícia Militar era focada nas pessoas que tinham } \\
\text { características com aparências criminosas; }\end{array}$ & Aumento da sensação de segurança do cidadão; \\
\hline $\begin{array}{l}\text { O Policial Militar não tinha vínculo com o turno e área de } \\
\text { serviço; }\end{array}$ & Aumento das ações de combate à criminalidade; \\
\hline Todos os fatos eram levados para a delegacia; & Fixação dos policiais militares ao turno e área de serviço; \\
\hline \multirow[t]{4}{*}{ Baixa integração entre a polícia e a comunidade. } & $\begin{array}{l}\text { Aumento da credibilidade da instituição por parte da comu- } \\
\text { nidade; }\end{array}$ \\
\hline & Conhecimento da Ronda da comunidade; \\
\hline & Mediação de conflitos; \\
\hline & $\begin{array}{l}\text { O foco dos policiais militares é na proteção dos } 98 \% \text { da popula- } \\
\text { ção (pessoas de boa conduta), sem esquecer os } 2 \% \text { (pessoas } \\
\text { à margem da lei). }\end{array}$ \\
\hline
\end{tabular}

Fonte: Studart (2009).

O trabalho da equipe do Ronda do Quarteirão está pautado na premissa de transmitir ao cidadão a sensação de segurança, pois o policial estará sempre por perto, realizando rondas a pé, de bicicleta, de motocicleta, de patinete ou por meio de viaturas apropriadas.

Existiram algumas tentativas de implantação do policiamento comunitário no Brasil, mas observa-se que os principais avanços foram no estado do Ceará, que, devido a relatos exitosos da população em relação ao programa Ronda do Quarteirão, tem servido de exemplo para outros estados brasileiros, fazendo com que despertasse a curiosidade nos governantes de outros estados em conhecer de perto essa experiência. No entanto, destaca-se que essa experiência também pode dar certo em todo o país, podendo ser uma alternativa para a melhoria da qualidade de vida da população brasileira; mas destaca-se, ainda, que muito há que ser feito, visto que o novo conceito de polícia mexe com os valores de um povo em relação à segurança. 


\section{Valores pessoais e cadeia de meios e fins}

Tamayo e Schwartz (1993) citam que a psicologia considera os valores como um dos motores que iniciam, orientam e controlam o comportamento humano. Os valores consistem em um projeto de vida e um esforço para atingir metas individuais ou coletivas. Um valor constitui uma crença estável em que certos modos de comportamento e objetivos de existência são pessoal ou socialmente aceitos (Karsaklian, 2004).

Diversos autores estudam a influência de valores pessoais no comportamento do consumidor. Os modelos da escala de valores de Rokeach e da escala de valores de Schwartz fazem-se relevantes para a literatura desse assunto (Engel, Blackwell e Miniard, 2000; Vilas Boas, 2005, 2007; Pimenta, 2008; Pimenta e Vilas Boas, 2008).

Neste contexto, observando Rokeach (1968) e Schwartz e Bilsky (1987), citados por Vilas Boas (2005:43-44), o conceito de valores se estabelece como:

conceitos abstratos ou crenças representando objetivos ou estados finais desejados. Constitui-se como o mais abstrato nível de cognição, não especificamente em relação a situações ou objetos, mas influenciando a percepção e avaliação destes. Portanto são imaginados como critérios utilizados pelos indivíduos como guias para avaliação de estímulos, como situações, pessoas e objetos. De forma geral assume-se que valores são universais, pois eles são praticamente os mesmos ao redor do mundo, mas a importância relativa atribuída a cada um deles varia.

Na visão de Schwartz (1992), os valores correspondem a objetivos que atendem ao interesse de indivíduos ou grupos. No modelo de Schwartz (1992), os valores pessoais podem ser classificados em quatro dimensões: abertura à mudança, autotranscendência, autoaprimoramento e conservadorismo. Estas dimensões permitem agrupar diferentes tipos de valores que influenciam o comportamento das pessoas. Esses tipos de valores, ou domínios motivacionais, são definidos no modelo e caracterizam 10 tipos:

v poder: poder social, autoridade, riqueza;

v realização: sucesso, capacidade, ambição, prazer, diversão;

v hedonismo: prazer, diversão, valores individuais e momentâneos;

v estimulação: vida sem rotina, excitante e desafiante;

v autodirecionamento: criatividade, curiosidade, liberdade;

v universalismo: cabeça aberta, justiça social, igualdade, proteção para o ambiente;

v benevolência: visar o bem-estar das pessoas, solicitude, honestidade, clemência;

v tradição: compromisso e aceitação de questões culturais onde se está inserido, humildade, devoção, gratidão; 
V conformidade: cortesia, obediência, honradez, moderação de ações que possam prejudicar terceiros;

v segurança: ordem social, limpeza, cuidado, harmonia social e individual.

Neste trabalho, os valores identificados na pesquisa de campo foram classificados conforme a perspectiva de Schwartz (1992).

Gutman (1982) promoveu um estudo sobre a means end-chain theory (MEC Theory) ao relacionar atributos, consequências e valores pessoais (objetivos ou estados desejados), com o propósito de oferecer uma estrutura conceitual capaz de interligar os valores dos consumidores a seus comportamentos.

A MEC Theory propõe que o conhecimento do produto ou serviço pelo consumidor é hierarquicamente organizado e está baseado na suposição de que consumidores veem produtos/serviços como meios para importantes fins, que são atingidos durante a seleção ou consumo destes.

Segundo Reynolds e colaboradores (1995), a teoria abarca vários níveis de abstração. Os níveis mais abstratos de conhecimento e significado subtendem níveis mais concretos de conhecimento e significado. Dessa forma, quanto mais alto for o nível de abstração, mais alto será o nível de hierarquia e, consequentemente, mais real a relação do indivíduo em seu processo de consumo.

"A cadeia de meios e fins é um modelo que procura explicar como a seleção de um produto ou serviço facilita a obtenção do estado fim desejado" (Gutman, 1982:60). Esse conceito explica três níveis de associações, que se iniciam em atributos de produtos ou serviços (A), partem para consequências (C) e de consequências partem para valores pessoais, formando a sequência A-C-V.

A teoria da cadeia de meios e fins demonstra por que, e como, os atributos dos produtos ou serviços são importantes, enfatizando que a compreensão desses vai além de suas características funcionais, ou seja, parte para o entendimento de seus significados na vida do indivíduo. São quatro os pressupostos que sustentam a teoria, de acordo com o comportamento do consumidor (Gutman, 1982):

- Os valores pessoais, definidos como estados finais desejados de existência, desempenham um papel dominante no processo de escolha;

- As pessoas lidam com uma diversidade de produtos e serviços que se apresentam como potenciais meios de satisfação de necessidades e valores;

- Todas as ações produzem consequências;

- Os indivíduos aprendem a associar uma consequência particular com uma ação particular.

Segundo Vilas Boas (2005), a forma como os indivíduos organizam seus pensamentos está ligada à infinidade de estímulos existentes ao redor do mundo. A capacidade de cada 
indivíduo de compreender e identificar esses estímulos é limitada às suas consequências pessoais, que os leva a uma situação de "categorização". O "processo de categorização é a forma que o consumidor utiliza para 'segmentar' seus ambientes em grupos significativos, criando equivalências entre estímulos não idênticos” (Vilas Boas, 2005:57).

Gutman (1982) ressalta que, embora os segmentos sejam agrupados com base em atributos, o que define a decisão de um consumidor ao adotar um produto/serviço é ser influenciado por valores e não por atributos, pois o indivíduo organiza os atributos percebidos em um produto/serviço com os estados futuros desejados.

Olson e Reynolds (1983, apud Veludo-de-Oliveira e Ikeda, 2006) propõem uma ampliação dos níveis da cadeia sugerida por Gutman (1982) ao subdividir os atributos em concretos e abstratos, as consequências em funcionais e psicológicas e os valores pessoais em terminais e instrumentais, recomendando uma cadeia de seis níveis.

Dentro da classificação de Olson e Reynolds (1983, apud Figueredo, 2007), são relacionados, por ordem de complexidade:

、 Atributos concretos: respostas referentes aos produtos que podem ser representadas em formas materiais distintas.

v Atributos abstratos: respostas referentes aos produtos que não podem ser representadas com uma forma material distinta.

v Consequências funcionais: respostas referentes ao uso, situações de uso, ou condições de uso que têm uma função utilitária.

v Consequências psicológicas: respostas referentes ao uso, situações de uso, ou condições de uso, que têm uma função expressiva ou hedônica.

v Valores instrumentais: respostas que se referem à própria pessoa e que tratam de competência ou moralidade.

、 Valores terminais: respostas que se referem à própria pessoa e que são ideais sociais ou de autorrealização.

\section{Metodologia}

Este trabalho é constituído de pesquisas bibliográficas sobre temas como: policiamento comunitário, valor para o cliente e teoria da cadeia de meios e fins. Esses conceitos permitiram fundamentar uma pesquisa de campo que utilizou a técnica laddering (Reynolds e Gutman, 1988) para coleta, análise e interpretação dos dados.

Foram realizadas 30 entrevistas em profundidade com pessoas que possuíssem faixa etária de 25 a 60 anos de idade, que residissem ou trabalhassem nos bairros do Centro de Fortaleza, Barra do Ceará e Jangurussu e que receberam visita comunitária (domiciliar ou em estabelecimento comercial) dos policiais do Ronda do Quarteirão, nos meses de agosto 
ou setembro de 2009. A consideração da faixa etária foi adotada pela orientação de os policiais procurarem na maioria das vezes pessoas adultas para explicarem o programa Ronda do Quarteirão em suas visitas. A escolha de entrevistar pessoas que receberam visitas nos meses de agosto ou setembro justifica-se pela imagem do Ronda do Quarteirão estar mais presente na mente destes entrevistados, pois se trata de visitas recentes, facilitando a classificação dos atributos, consequências e valores. Escolheram-se os três bairros que apresentaram o maior índice de criminalidade no município de Fortaleza, segundo a Coordenadoria Integrada de Operações de Segurança (Ciops), sendo eles: Centro, Jangurussu e Barra do Ceará.

As entrevistas foram gravadas e, posteriormente, transcritas para que seus dados fossem depois utilizados na investigação do consumo/utilização dos serviços do Ronda do Quarteirão.

Antes de iniciar a entrevista propriamente dita, em que se adotou a técnica de laddering, os entrevistados responderam a um questionário sociodemográfico que engloba questões como idade, escolaridade, quantidade de membros da família, estado civil e renda. Estes dados foram importantes para traçar o perfil dos usuários dos serviços do Ronda do Quarteirão que formaram a amostra.

O objetivo principal da técnica laddering é especificar a sequência (ou estrutura) de resultados originais da escolha e consumo de um produto ou serviço que se prolongam desde a identificação dos atributos, revelando as consequências ou benefícios finais e chegando aos valores pessoais (Gutman, 1991).

As fases da laddering, segundo Reynolds e Gutman (1988), compreendem:

จ Levantamento da percepção do consumidor (usuário de serviços) por meio de perguntas do tipo: "por que isto é importante para você?" de forma repetitiva. À medida que o entrevistado revela um atributo, é questionado sobre sua importância até revelar os valores pessoais relacionados a este atributo;

v Análise de conteúdo e padronização dos elementos-chave identificados na entrevista. Distinção entre atributos, consequências e valores;

v Construção de uma tabela (matriz de implicação), que representa a quantidade de conexões entre os elementos-chave, ou seja, a quantidade de vezes que cada elemento direciona ao alcance de cada atributo, consequência ou valor. Esta tabela servirá para a construção do mapa hierárquico de valor, pois contabiliza as relações diretas e indiretas entre os elementos.

v Construção do mapa hierárquico de valor (HVM), que corresponde ao mapeamento das relações existentes entre os elementos identificados na matriz de implicação. Consiste na estruturação de cadeias meios-fins, que parte da primeira linha de implicação e vai até a última. Corresponde a um diagrama em forma de árvore e representa graficamente as conexões entre os atributos, consequências e valores.

Para iniciar a entrevista, fez-se uma pergunta-chave, tipo: "Quando eu falo Ronda do Quarteirão, que características (atributos) você considera mais importântes?” O objetivo des- 
se primeiro passo foi fazer com que o respondente mencionasse os principais atributos do serviço pesquisado. O direcionamento subsequente da entrevista foi determinado pela resposta inicial, pelas sondagens do entrevistador para aprofundar a pesquisa e pelas respostas do entrevistado.

As entrevistas foram agendadas com antecedência por telefone e foram realizados três pré-testes com pessoas de características semelhantes as da amostra, com o intuito de detectar falhas no processo de pesquisa. Para chegar às 30 entrevistas satisfatórias, realizaram-se 42 entrevistas, das quais 12 foram descartadas por não conter dados suficientes que dessem suporte à construção do Mapa Hierárquico de Valor. As entrevistas foram realizadas nos meses de outubro a dezembro de 2009 e tiveram duração entre 25 e 30 minutos.

O processo para análise se dividiu da seguinte forma, conforme proposta por Reynolds e Gutman (1988): análise do conteúdo das entrevistas; criação da matriz de implicação, construção do mapa hierárquico de valor e determinação das orientações de percepções dominantes.

Adotaram-se os softwares Laddermap, desenvolvido por Gengler em 1995, e o Mecanalyst, desenvolvido e utilizado por Naspeti e Zanoli em 2004, para análise dos ladders e consequentemente construção do HVM.

As informações obtidas na matriz de implicação deram suporte para a construção do mapa hierárquico de valor (HVM), sendo este a conexão de todas as cadeias que são formadas, levando em consideração os links da matriz implicação na relação entre os elementos. (Vilas Boas, 2005).

Reynolds e Gutman (1988) ressaltam que, na etapa de construção do Mapa Hierárquico de Valor (HVM), é essencial definir-se o ponto de corte, que geralmente abrange de $75 \%$ a $80 \%$ dos relacionamentos apresentados na matriz de implicação. Pode-se entender como ponto de corte a quantidade de vezes que determinada relação ocorre para que seja considerada relevante e, consequentemente, seja utilizada no HVM (Vilas Boas, 2005). As relações com baixa incidência não são consideradas para comporem o HVM.

Segundo as etapas sugeridas por Reynolds e Gutman (1988), a última etapa refere-se à identificação das orientações de valores dominantes, ou seja, identificar quais cadeias mais contribuíram para o alcance do resultado. Para atender a esse propósito, foram realizadas análises no HVM e, ainda, elaborado um quadro explicativo (quadro 5) sobre as características dos atributos, consequências e valores, bem como suas conexões.

\section{Análise e discussão dos resultados}

A seguir serão mostrados os sinônimos dos elementos identificados na pesquisa, agrupados e codificados conforme seu significado na percepção dos entrevistados. Relacionaram-se os resultados com as definições teóricas de Schwartz (1992) sobre valores pessoais. Apresentarse-á o perfil sociodemográfico dos entrevistados e ao final do tópico a matriz de implicação e o mapa hierárquico de valor. 
De acordo com o perfil sociodemográfico, a grande maioria dos usuários dos serviços do Ronda do Quarteirão pesquisados foi do sexo feminino, com 60\%. Quanto à faixa etária, houve predominância de 25 a 30 anos de idade, com 43\%. Em relação ao estado civil, 54\% eram solteiros, seguidos de $43 \%$ casados e $3 \%$ viúvos. Quanto à escolaridade, a maioria dos entrevistados possuía ensino médio completo, perfazendo um percentual de 40\%. Nota-se que a renda familiar predominante na amostra foi de 2,5 a 4 salários mínimos, representando $37 \%$.

Para a classificação dos atributos, consequências e valores, aplicou-se uma numeração para cada código-resumo para facilitar a identificação e interpretação dos resultados a serem obtidos no mapa hierárquico de valor.

Salienta-se que a codificação aplicada aos atributos, consequências e valores baseou-se no seguinte direcionamento:

- Classificação dos atributos: por meio da Lista Resumo de Sinônimos, consideraram-se os aspectos concretos do serviço, como automóvel, rapidez, tecnologia, e os aspectos abstratos, como preparo dos policiais e credibilidade do Ronda. Foram identificados 11 atributos, conforme quadro 2.

v Classificação das consequências: foram classificadas em funcionais e psicológicas, seguindo em direção à abstração das expressões citadas pelos entrevistados, com o propósito de gerar uma lista de códigos-resumo que auxiliasse na construção dos níveis das escalas dos respondentes, de acordo com a sequência da proposta da laddering. No quadro 2 (Lista Resumo de Significados), foram numerados 15 códigos-resumo referentes às consequências funcionais e psicológicas.

v Classificação dos valores: utilizaram-se como parâmetro para a classificação dos valores os Tipos Motivacionais de Schwartz (1992), para identificar as várias possibilidades e os caminhos percorridos pelos usuários para atingir seus estados desejados. Foram evidenciados nove valores na fala dos entrevistados, conforme quadro 2.

Quadro 2

Lista resumo de sinônimos

\begin{tabular}{|lll|}
\hline Atributos & Consequências & Valores \\
\hline 1. agilidade & 12. ajudar as pessoas & 27. amar o que faz \\
2. armamentos & 13. atender bem & 28. amizade \\
3. credibilidade & 14. comunicação com o cidadão & 29. cidadania \\
4. fardamento & 15. confiança & 30. defender a pátria \\
5. polícia presente & 16. conforto & 31. felicidade \\
6. preparo dos policiais & 17. diminuir o estresse & 32. honestidade \\
7. processo seletivo diferenciado & 18. espelhar-se na polícia & 33. satisfação \\
\hline
\end{tabular}




\begin{tabular}{|lll|}
\hline Atributos & Consequências & Valores \\
\hline 8. ronda & 19. integração polícia-comunidade & 34. segurança \\
9. soldado & 20. mexer com o psicológico & 35. sentir-se útil à sociedade \\
10. tecnologia & 21. sentimento de harmonia & \\
11. viatura & 22. sentir-se bem \\
& 23. sentir-se protegido \\
& 24. sentir-se respeitado \\
& 25. ser ético \\
& 26. ter lazer & \\
\hline
\end{tabular}

Fonte: Dados da pesquisa.

Classificaram-se as definições dos sinônimos por tipos, conforme a literatura de Reynolds e Gutman (1988). Os atributos concretos representam características físicas ou aparentes, considerados de fácil identificação. Os seguintes códigos foram classificados como atributos concretos por se adequarem a esta definição: 1, 2, 4, 8, 9, 10 e 11. Os demais atributos foram classificados como abstratos por sua subjetividade, conforme descrito nas definições acima. Fazem parte dessa classificação os códigos 3, 5, 6 e 7.

O nível de consequências dividiu-se em funcionais e psicológicas. De acordo com Reynolds e Gutman (1988), as consequências funcionais são diretas e perceptíveis ao usuário, enquanto as consequências psicológicas são indiretas, correspondem a crenças, um benefício psicológico ou social. Os códigos 12, 14 e 19 foram definidos como consequências funcionais. Como consequências psicológicas, foram definidos os códigos 13, 15, 16, 17, 18, 20, 21, 22, 23, 24, 25 e 26.

Os valores foram classificados em instrumentais e terminais. Valores instrumentais representam atitudes (padrões de comportamentos) dos usuários e valores terminais representam o estado desejado, como viver em paz. Foram definidos como valores instrumentais os códigos 29 e 35 e como valores terminais os códigos 27, 28, 30, 31, 32, 33 e 34.

A seguir, relacionaram-se os valores obtidos na pesquisa com as definições do Modelo de Schwartz (1992), que estão classificados em quatro dimensões: abertura à mudança, autotranscendência, autoaprimoramento e conservadorismo, no intuito de classificar os tipos de valores dos usuários do serviço do Ronda do Quarteirão. 
Quadro 3

Relação entre a classificação dos valores de Schwartz e os valores dos entrevistados

\begin{tabular}{|c|c|c|c|}
\hline Dimensões de Valores & Tipo de Valor & Definições de Valores & $\begin{array}{l}\text { Valores obtidos na } \\
\text { pesquisa }\end{array}$ \\
\hline \multirow[t]{3}{*}{ Aberto à mudança } & Autodireção & $\begin{array}{l}\text { Criatividade, liberdade, independência, } \\
\text { curiosidade, escolhe suas próprias metas. }\end{array}$ & $\begin{array}{l}\text { 34. Segurança (viver em paz, } \\
\text { liberdade) }\end{array}$ \\
\hline & Estimulação & $\begin{array}{l}\text { Ousadia, uma vida variada, uma vida } \\
\text { excitante. }\end{array}$ & \\
\hline & Hedonismo & Prazer, aproveitar a vida. & $\begin{array}{l}\text { 28. Amizade } \\
\text { 31. Felicidade } \\
\text { 33. Satisfação }\end{array}$ \\
\hline \multirow[t]{2}{*}{ Autoaprimoramento } & Realização & Bem-sucedido, capaz, ambicioso, influente. & 27. Amar o que faz \\
\hline & Poder & Poder social, autoridade, riqueza. & \\
\hline \multirow[t]{3}{*}{ Conservadorismo } & Segurança & $\begin{array}{l}\text { Segurança familiar, segurança nacional, } \\
\text { ordem social, reciprocidade de valores. }\end{array}$ & 30. Defender a pátria \\
\hline & Conformidade & $\begin{array}{l}\text { Autodisciplina, obediência, educação, } \\
\text { respeitar os pais e os mais velhos. }\end{array}$ & \\
\hline & Tradição & $\begin{array}{l}\text { Humilde, respeito pela tradição, devoto, } \\
\text { vida espiritual, moderado. }\end{array}$ & \\
\hline \multirow[t]{2}{*}{ Autotranscendência } & Benevolência & Útil, honesto, que perdoa, leal, responsável. & $\begin{array}{l}\text { 32. Honestidade } \\
\text { 35. Sentir-se útil à socie- } \\
\text { dade }\end{array}$ \\
\hline & Universalismo & $\begin{array}{l}\text { Compreensão, sabedoria, justiça social, } \\
\text { igualdade, um mundo de paz, um mundo } \\
\text { de beleza, protetor do meio ambiente }\end{array}$ & 29. Cidadania \\
\hline
\end{tabular}

Fontes: Adaptado de Schwartz (1992) e Schwartz e Sagie (2000).

Verificou-se, no quadro 3, que as quatro dimensões propostas por Schwartz (1992) concentram os valores apresentados pelos usuários dos serviços do Ronda do Quarteirão, mas destaca-se que os entrevitados têm uma maior tendência na dimensão "Aberto à mudança", onde se concentram quatro valores: (34) Segurança, (28) Amizade, (31) Felicidade e (33) Satisfação.

\subsection{Matriz de implicação}

Esta etapa caracterizou-se pela representação de todas as relações que foram identificadas nas escalas construídas a partir das entrevistas. A matriz de implicação é considerada na laddering um instrumento de importante auxílio para a interpretação das entrevistas, tornando-se possível mensurar os elementos obtidos de forma confiável, fazendo-se chegar à confirmação das percepções referentes aos valores inerentes aos usuários dos serviços do Ronda do Quarteirão, na cidade de Fortaleza (CE). 
A matriz de implicação permite a análise numérica das relações entre os elementos (atributos, consequências e valores) e fornece coordenadas para a construção do mapa hieráriquico de valor, que consiste em um diagrama que mostra as sequências de relações formadas pelas escalas (ladders) de elementos coligados. (Pimenta, 2008:89)

Conforme apresentado na metodologia, levaram-se em consideração para representação na matriz de implicação tanto as relações diretas quanto as indiretas. O valor correspondente ao total de relações é representado em forma decimal. De acordo com Reynolds e Gutman (1988), as ligações diretas correspondem àquelas em que um elemento está diretamente ligado a outro, localizando-se à esquerda do decimal. As ligações indiretas ficam contabilizadas à esquerda do decimal, dentro das células da matriz.

Vale ressaltar que nas situações em que uma mesma relação ocorre mais de uma vez dentro de escalas obtidas por um mesmo entrevistado, a relação é contabilizada uma única vez, seguindo as orientações metodológicas, de forma a não distorcer a posterior construção do mapa hierárquico de valores (Vilas Boas, 2005).

$\mathrm{O}$ quadro 4 demostra os caminhos percorridos por um entrevistado para atingir suas metas ou estados fins desejados.

Quadro 4

Níveis da escala do usuário dos serviços do Ronda do Quarteirão

\begin{tabular}{|c|c|c|c|c|c|}
\hline \multicolumn{2}{|c|}{ Nível do Atributo } & \multicolumn{2}{|c|}{ Nível da Consequência } & \multicolumn{2}{|c|}{ Nível do Valor } \\
\hline Concreto & Abstrato & Funcional & Psicológica & Instrumental & Terminal \\
\hline \multirow[t]{2}{*}{ 11. viatura } & & & 13. atender bem & & \\
\hline & $\begin{array}{l}\text { 6. preparo dos } \\
\text { policiais }\end{array}$ & $\begin{array}{l}\text { 14. comunicação } \\
\text { com o cidadão }\end{array}$ & $\begin{array}{l}\text { 24. sentir-se } \\
\text { respeitado }\end{array}$ & & \\
\hline \multirow[t]{2}{*}{ 4. fardamento } & & & $\begin{array}{l}\text { 24. sentir-se } \\
\text { respeitado }\end{array}$ & & 34. segurança \\
\hline & $\begin{array}{l}\text { 6. preparo dos } \\
\text { policiais }\end{array}$ & & 13. atender bem & 29. cidadania & \\
\hline
\end{tabular}

Fonte: Dados da pesquisa.

Estes níveis de escalas representam as sequências que formam as ladders, as quais conduzirão a interpretação do comportamento do usuário dos serviços de segurança pública.

Observa-se que o quadro 4 está dividido em três níveis que representam a estrutura A$\mathrm{C}-\mathrm{V}$ (atributos, consequências e valores) e, por sua vez, estes se subdividem, formando uma escala de seis níveis: atributos concretos, atributos abstratos, consequências funcionais, consequências psicológicas, valores instrumentais e valores terminais.

A matriz de implicação fornece o número de vezes que estas ligações venham a se repetir em uma entrevista. Observa-se também, no quadro 4, a formação de mais de uma ladder na mesma entrevista, cujo ponto de partida é o atributo abstrato 6 (Preparo dos Policiais), 
que leva à consequência funcional 14 (Comunicação com o Cidadão), que leva à consequência psicológica 24 (Sentir-se Respeitado). O mesmo atributo percorre outro caminho para chegar ao valor 29 (Cidadania): atributo 6 (Preparo dos Policiais) é conduzido à consequência psicológica 13 (Atender Bem), que chega ao valor instrumental 29 (Cidadania).

A tabela 1 explica de forma sucinta a tabela 2, ou seja, os valores estão representados em forma de fração, ficando as relações diretas à esquerda e as indiretas à direita do decimal.

Tabela 1

\section{Exemplo da forma de representação do número de ocorrências na matriz de implicação}

\begin{tabular}{|c|c|c|c|c|c|}
\hline & & & 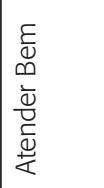 & 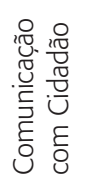 & \\
\hline \multicolumn{2}{|c|}{ Códigos resumo } & \multicolumn{2}{|l|}{ Códigos resumo } & 14 & \multirow{8}{*}{$\begin{array}{l}\text { Implica que ocorreram } \\
\text { nove relações diretas e } \\
\text { duas relações indiretas } \\
\text { entre os elementos } 6 \\
\text { (Preparo dos Policiais) } \\
\text { e } 13 \text { (Atender Bem) no } \\
\text { total de evidências. }\end{array}$} \\
\hline 1 & Agilidade & & 5.0 & & \\
\hline 2 & Armamentos & & 2.0 & & \\
\hline 3 & Credibilidade & & 1.0 & & \\
\hline 4 & Fardamento & & & & \\
\hline 5 & Polícia Presente & & 3.1 & 2.0 & \\
\hline 6 & Preparo dos Policiais & & 9.2 & 3.0 & \\
\hline 7 & $\begin{array}{l}\text { Processo Seletivo Di- } \\
\text { ferenciado }\end{array}$ & & 3.1 & & \\
\hline
\end{tabular}

Fonte: Elaborada pelos autores.

Como forma de exemplo para a análise da matriz (tabela 2), cabe ressaltar algumas relações:

Ressalta-se a relação entre o atributo 6 e a consequência 13 (linha 6 e coluna 13) apresentando a incidência de nove ligações diretas e duas ligações indiretas. A ligação entre o atributo 5 e a consequência 23 (linha 5 e coluna 23) apresentam a incidência de sete ligações diretas. A ligação entre o mesmo atributo 5 com o valor 34 (linha 1 e coluna 34) representou 10 ligações indiretas e nenhuma direta, ilustrando a ideia de que as ligações indiretas ocorrem entre elementos não adjacentes, como no caso deste atributo que necessita de elementos intermediários (consequências) para atingir o valor 35 .

Podem-se observar, na matriz de implicação apresentada na tabela 2, todas as ligações diretas e indiretas obtidas na pesquisa. Os registros da matriz servirão como coordenadas para a construção do mapa hierárquico de valor (HVM). 


\subsection{Mapa hierárquico de valor}

Conforme a metodologia, o mapa hierárquico de valor (HVM) é o último passo da técnica laddering. O HVM apresenta graficamente os atributos, as consequências e os valores com maior frequência. Abaixo se encontram os resultados da utilização dos três pontos de corte, a escolha e a justificativa da mesma:

- Ponto de corte 2: 217 ligações totais, 158 ligações ativas, 20 elementos, abrange 72,8\% do total das relações;

v Ponto de corte 3: 217 ligações totais, 136 ligações ativas, 14 elementos, abrange 62,7\% do total das relações;

- Ponto de corte 4: 217 ligações totais, 112 ligações ativas, 10 elementos, abrange 51,7\% do total das relações.

Nesta pesquisa, optou-se pelo ponto de corte 2 , já que representou uma incidência considerável dos principais elementos, além de o HVM ficar graficamente claro e objetivo, a ponto de explicar tal comportamento e seus motivos. De acordo com Pimenta (2008), a recomendação do ponto de corte é para que o HVM tenha uma capacidade explicativa mais apurada possível sobre as reais e principais características dos entrevistados em busca de satisfação de uma necessidade por meio de atributos, consequências e valores.

Com a utilização do ponto de corte 2, identificou-se 20 elementos, sendo 10 atributos, sete consequências e três valores, resultando em 158 ligações ativas de um total de 217 ligações, correspondendo a $72,8 \%$ das ligações totais. Justifica-se, portanto, a escolha pelo ponto de corte 2 por descartar apenas as relações com menos de dois elementos, enfatizando a compreensão dos elementos mais relevantes que formam a percepção dos usuários dos serviços do Ronda do Quarteirão.

A figura a seguir apresenta o Mapa Hierárquico de Valor obtido a partir das entrevistas com os usuários dos serviços do Ronda do Quarteirão nos bairros do Centro, Jangurussu e Barra do Ceará, na cidade de Fortaleza (CE).

A análise da figura constituiu-se na identificação dos atributos que apresentaram maior frequência entre os entrevistados, formando, assim, cadeias significativas que conduziram aos valores, permitindo maior amplitude na interpretação do comportamento do usuário dos serviços do Ronda do Quarteirão.

Foram identificadas no mapa 24 cadeias advindas dos atributos (1) Agilidade, (2) Armamentos, (3) Credibilidade, (4) Fardamento, (5) Polícia presente, (6) Preparo dos Policiais, (7) Processo Seletivo Diferenciado, (8) Ronda, (9) Soldado, (11) Viatura.

A partir do atributo (1) Agilidade, quatro cadeias foram formadas: 1-12-34; 1-13-29; 1-23-34; 1-13-34.

As cadeias que partem do atributo (2) Armamentos representam as percepções dos usuários dos serviços do Ronda do Quarteirão sobre o tipo de armas utilizadas pelos policiais, se são compatíveis ou melhores do que as utilizadas pelos bandidos. Fazem parte deste atributo duas cadeias: 2-23-34 e 2-13-29. 


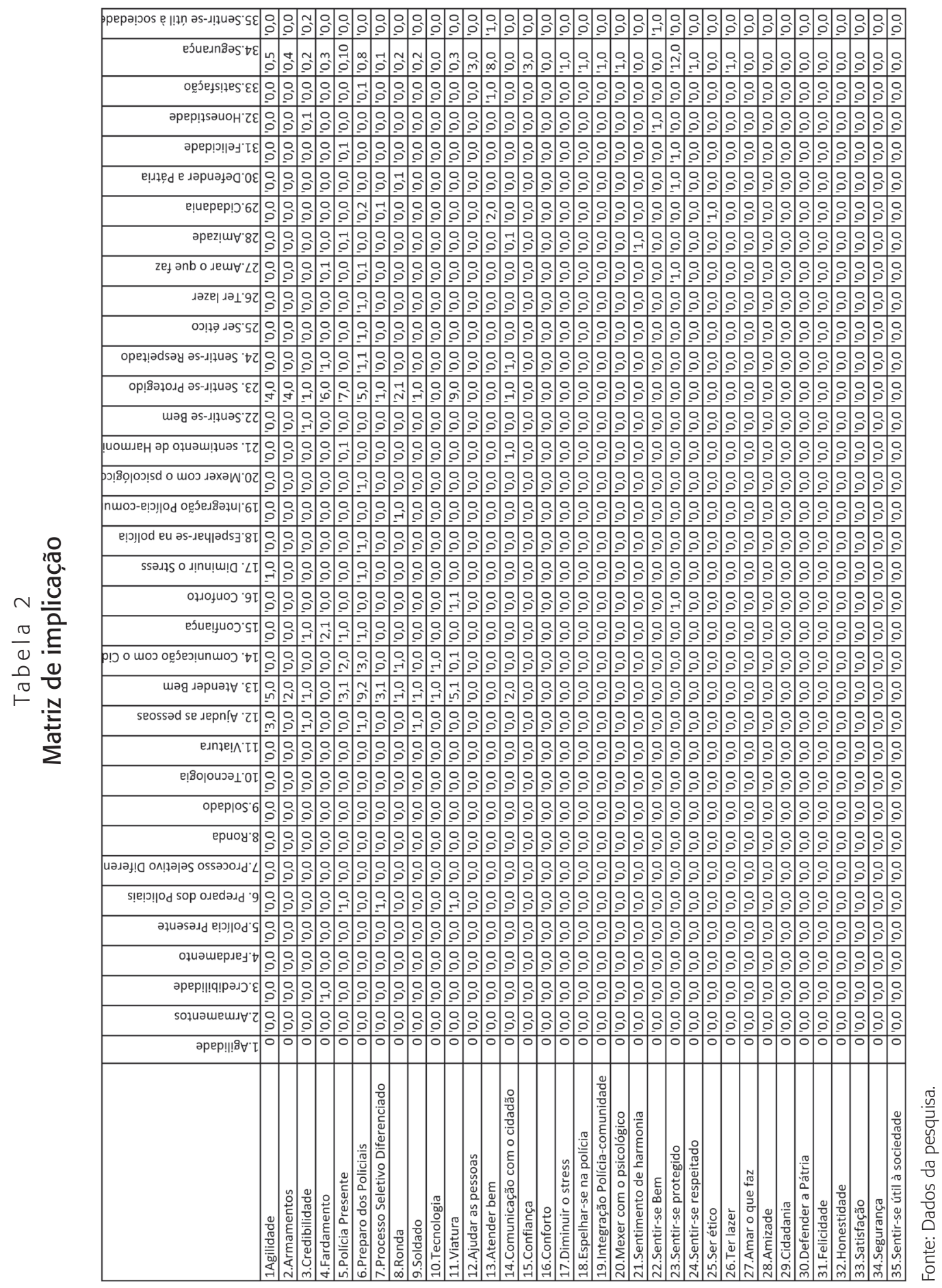




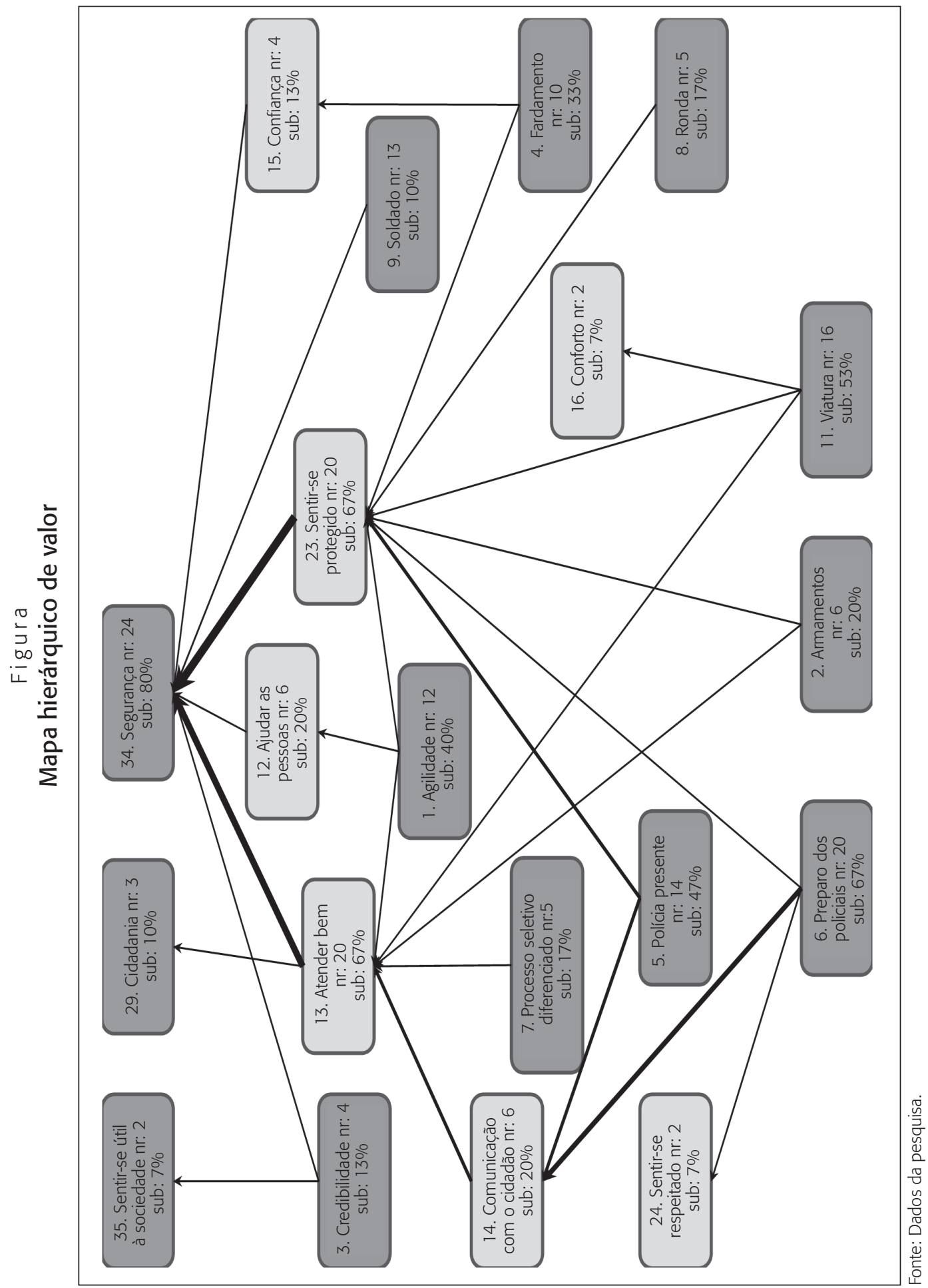

RAP - Rio de Janeiro 46(1):333-57, jan./fev. 2012 
O atributo (3) Credibilidade é importante na percepção do usuário dos serviços do Ronda do Quarteirão por significar "reputação", "caráter" e "autoridade". Observaram-se duas cadeias no mapa hierárquico de valor, sendo elas: 3-34 e 3-35.

O atributo concreto (4) Fardamento apresenta no mapa hierárquico de valor duas cadeias: 4-15-34 e 4-23-34. Observa-se que as duas cadeias são conduzidas a um mesmo valor (34) Segurança, mas partem de caminhos diferentes: a farda do policial transmite (15) Confiança ao cidadão no primeiro e (23) Sentimento de Proteção no segundo.

O atributo (5) Polícia Presente apresentou três cadeias: 5-23-34; 5-14-13-34; 5-14-1329. Este atributo representa a aproximação do policial com o cidadão. Nestas cadeias, analisa-se o comportamento do usuário como uma pessoa que preza pela relação que existe entre a polícia e o cidadão, por meio da "conversa", a partir da qual o policial passa a conhecer as pessoas que residem ou trabalham em sua área de atuação.

O atributo (6) Preparo dos Policiais é um atributo importante no processo de avaliação da percepção do usuário dos serviços do Ronda do Quarteirão; por se tratar de um serviço público, o cidadão percebe que os policiais passam por treinamentos e capacitações para poder atender bem as pessoas que precisam deste serviço. No mapa, este atributo aparece com o maior número de cadeias, ou seja, quatro cadeias: 6-14-13-29; 6-24; 6-14-13-34; 6-23-34.

O atributo (7) Processo Seletivo Diferenciado demonstra que o cidadão está atento sobre a seleção do policial do Ronda. O significado deste atributo apareceu como "mais rígido" e "mais exigente". Neste atributo, encontrou-se a construção de duas cadeias, sendo elas: 713-29 e 7-13-34.

O atributo (8) Ronda apareceu no HVM com uma única cadeia: 8-23-34, mostrando que os entrevistados que citaram este atributo percebem que a circulação da viatura com alta frequência em uma mesma área eleva o sentimento de proteção que conduz ao valor (34) Segurança.

O atributo (9) Soldado, assim como o atributo 8, apresentou uma única cadeia, mas aquele atributo aparece no HVM como uma cadeia de apenas duas ligações: 9-34, ou seja, a figura do policial leva o cidadão à tranquilidade.

O atributo concreto (11) Viatura apresenta-se no HVM com três cadeias: 11-16; 11-1329 e 11-13-34. Este atributo destaca que a viatura do Ronda é de fácil identificação pelo cidadão; uma Hi-lux, na percepção dos entrevistados, é um carro apropriado para tal serviço.

O Quadro 5 relaciona os atributos encontrados no HVM com as percepções de valores dos usuários dos serviços do Ronda do Quarteirão, ou seja, os atributos e consequências como forma de alcance desses valores. 


\section{Quadro 5 \\ Relação dos atributos dos serviços do Ronda do Quarteirão com os valores identificados no mapa hierárquico de valor}

\begin{tabular}{|c|c|c|}
\hline Atributos & $\begin{array}{l}\text { Valores } \\
\text { apresentados no } \\
\text { HVM }\end{array}$ & Percepção do Usuário dos Serviços do Ronda do Quarteirão \\
\hline 1. Agilidade & $\begin{array}{l}\text { 29. Cidadania } \\
\text { 34. Segurança }\end{array}$ & $\begin{array}{l}\text { Crença de que a Agilidade do Ronda do Quarteirão chegar ao local da } \\
\text { ocorrência proporciona Cidadania e Segurança. }\end{array}$ \\
\hline 2. Armamentos & $\begin{array}{l}\text { 29. Cidadania } \\
\text { 34. Segurança }\end{array}$ & $\begin{array}{l}\text { As armas adotadas pelos policiais do Ronda do Quarteirão transmitem um } \\
\text { sentimento de proteção e são importantes para um bom atendimento. }\end{array}$ \\
\hline 3. Credibilidade & $\begin{array}{l}\text { 34. Segurança } \\
\text { 35. Sentir-se útil à } \\
\text { sociedade }\end{array}$ & $\begin{array}{l}\text { Esta percepção implica que o caráter do policial bem como a autoridade } \\
\text { proporcionam uma sensação de que todos estão trabalhando para atingir } \\
\text { o bem comum da sociedade. }\end{array}$ \\
\hline 4. Fardamento & 34. Segurança & $\begin{array}{l}\text { A farda utilizada pelo policial do Ronda passa confiança para o cidadão e } \\
\text { ele se sente protegido para chegar ao nível de segurança pretendido. }\end{array}$ \\
\hline 5. Polícia Presente & $\begin{array}{l}\text { 29. Cidadania } \\
\text { 34. Segurança }\end{array}$ & $\begin{array}{l}\text { Acredita que, com o Programa Ronda do Quarteirão, a polícia está sempre } \\
\text { perto do cidadão. Com esta percepção ele entende que está mais } \\
\text { protegido, ao mesmo tempo que o policial se comunica com a população } \\
\text { para entender a realidade de cada comunidade e passa a atender melhor } \\
\text { o cidadão. }\end{array}$ \\
\hline 6. Preparo dos Policiais & $\begin{array}{l}\text { 29. Cidadania } \\
\text { 34. Segurança }\end{array}$ & $\begin{array}{l}\text { O usuário dos serviços do Ronda do Quarteirão percebe que os policiais } \\
\text { são treinados e capacitados para atender a população. O cidadão } \\
\text { considera o policial educado, comparando-o com a polícia comum e } \\
\text { ressalta a importância para se ter cidadania e viver em paz. }\end{array}$ \\
\hline $\begin{array}{l}\text { 7. Processo Seletivo } \\
\text { Diferenciado }\end{array}$ & $\begin{array}{l}\text { 29. Cidadania } \\
\text { 34. Segurança }\end{array}$ & $\begin{array}{l}\text { A exigência e rigidez durante o processo seletivo do militar é reconhecida } \\
\text { pelo cidadão, acreditando este que com os critérios diferenciados na } \\
\text { seleção do pessoal possa-se atingir a Cidadania e Segurança. }\end{array}$ \\
\hline 8. Ronda & 34. Segurança & $\begin{array}{l}\text { O cidadão percebe que as viaturas circulam com frequência em uma } \\
\text { determinada área, elevando a sensação de proteção para se atingir a } \\
\text { Segurança. }\end{array}$ \\
\hline 9. Soldado & 34. Segurança & $\begin{array}{l}\text { A figura do soldado leva à crença da conquista pela segurança, de acordo } \\
\text { com a percepção dos entrevistados. }\end{array}$ \\
\hline 10. Viatura & $\begin{array}{l}\text { 29. Cidadania } \\
\text { 34. Segurança }\end{array}$ & $\begin{array}{l}\text { A viatura é percebida pelo cidadão como um carro apropriado para o } \\
\text { serviço de segurança. Um carro ágil como o utilizado pelos bandidos, } \\
\text { que transmite conforto para o policial e para o cidadão, podendo aquele } \\
\text { atender melhor o cidadão. }\end{array}$ \\
\hline
\end{tabular}

Fonte: Dados da pesquisa.

\section{Considerações finais}

O objetivo principal desta pesquisa foi analisar a estrutura de valores dos usuários dos serviços do Ronda do Quarteirão da ótica da teoria da cadeia de meios e fins. Para atingimento deste 
objetivo, utilizou-se a técnica de laddering que geralmente é empregada para descobrir os valores predominantes dos consumidores em relação a determinados produtos ou serviços. Por meio de entrevistas em profundidade com 30 usuários dos serviços do Ronda do Quarteirão, foi possível identificar 11 atributos, 15 consequências e nove valores, bem como as conexões cognitivas entre estes elementos. As cadeias dominantes estão relacionadas aos atributos (1) Agilidade, com 4 cadeias: 1-12-34; 1-13-29; 1-23-34; 1-13-34, (6) Preparo dos Policiais, com 4 cadeias: 6-14-13-29; 6-24; 6-14-13-34; 6-23-34 e (5) Polícia Presente, com 3 cadeias: 5-2334; 5-14-13-34; 5-14-13-29. Os usuários percebem a conexão destes atributos, e respectivas consequências, com valores pessoais como: segurança e cidadania.

Definidos quais valores são pertencentes à percepção deste usuário, a escala de Schwartz (1992) mostrou-se útil para classificar estes valores de acordo com as dimensões: Abertura à Mudanças, Autoaprimoramento, Conservadorismo e Autotranscendência. Observou-se que os valores dos usuários da pesquisa concentram-se nas quatro dimensões propostas por Schwartz (1992).

Observam-se quatro valores individuais e cinco valores coletivos. Os valores considerados individuais são: 27 (Amar o que faz), 31 (Felicidade), 32 (Honestidade) e 34 (Segurança). Os demais valores demonstram uma preocupação maior com a sociedade, portanto, foram considerados como valores coletivos. Sendo eles: 28 (Amizade), 29 (Cidadania), 30 (Defender a Pátria), 33 (Satisfação) e 35 (Sentir-se Útil à Sociedade). Apesar de apresentar um maior número de valores coletivos, ressalta-se que o valor (34) Segurança foi identificado em 24 de 30 entrevistas, representando significados que classificam-no como valor individual. Neste contexto, considera-se o perfil do usuário dos serviços do Ronda do Quarteirão com ênfase individualista em primeiro plano. Tal característica pode ser fortalecida na análise sociodemográfica dos entrevistados, que na maioria são solteiros e jovens com faixa etária entre 25 e 30 anos de idade.

Tendo como ponto de partida a análise dos atributos, elementos do primeiro nível da estrutura laddering, para alcançar os valores, último nível da técnica, foi possível construir o Mapa Hierárquico de Valor (HVM).

Além da evidência destes elementos e sua interconexão, destaca-se a contribuição deste artigo no sentido de analisar um serviço público, da ótica da população, por meio da técnica laddering, que anteriormente vinha sendo utilizada para analisar mercados consumidores de serviços (Flores Neto e Silveira, 2007; Veludo-de-Oliveira e Ikeda, 2006) e de produtos (Vilas Boas, 2005; Padel e Foster, 2005; Krystallis, Maglaras e Mamalis, 2008).

\subsection{Implicações gerenciais}

Compreender mais profundamente a maneira e o que leva o indivíduo à utilização de um serviço público extrai significados relevantes tanto para a academia quanto para as instituições públicas, pois é justamente isto que define e classifica a qualidade e a importância desse serviço. 
A teoria da cadeia de meios e fins apresenta um método que torna mais compreensível a decisão do usuário do serviço público, revelando significados que levam à abstração, pois dá ênfase a todos os níveis (benefícios e abstrações), tornando-se essencial para traçar estratégias eficazes, visto que o ideal não é apenas considerar o benefício de um produto ou serviço, mas, sim, o que está por trás deles.

Nesta pesquisa procurou-se compreender os usuários dos serviços de policiamento comunitário - O Ronda do Quarteirão - por se tratar de um "cliente" ainda não estudado com o enfoque mercadológico, além de o serviço ser considerado novo no Brasil e envolver a mudança cultural de um povo.

Entretanto, encontrar o real motivo da utilização de um serviço de segurança pública permite a identificação profunda do usuário com o serviço, ou seja, direciona o serviço para uma população mais voltada à busca de valores como Cidadania e Viver em Paz. Salienta-se que o aprofundamento e a adoção de diretrizes envolvendo teorias do marketing de relacionamento podem tornar-se complementares às teorias do Comportamento do Consumidor, por se tratar de um tipo de serviço com foco no relacionamento "polícia e cidadão".

Percebeu-se que as pessoas estão abertas às mudanças e que o conceito de policiamento comunitário está sendo bem trabalhado pela gestão pública para os três bairros que apresentam maior índice de violência à medida que os entrevistados percebem desde a ronda frequente das viaturas nas ruas até a leveza das cores na farda dos policiais, associando, desta forma, o Programa Ronda do Quarteirão com valores como Amizade, Cidadania, Defender a Pátria e Viver em Paz.

Por fim, este tipo de pesquisa permite a melhor compreensão dos objetivos da vida, sendo eles indispensáveis para analisar se as estratégias adotadas pelas organizações estão sendo eficazes e para auxílio na criação de novas estratégias de marketing direcionadas a públicos, produtos e serviços específicos.

\subsection{Limitações da pesquisa}

Encontraram-se limitações na utilização do software Laddermap, visto que é um software restrito a certos sistemas operacionais, não sendo compatível com sistemas modernos como Windows Vista e Windows 7 da Microsoft. Outra limitação está na inserção de dados, suportando poucas expressões ou frases curtas para o significado dos atributos, consequências e valores. O software também não reconhecia palavras acentuadas ou com cedilha, fazendo-se necessária uma correção ortográfica posterior. O arquivo gerado pelo Laddermap foi usado em outro software (Mecanalyst) por apresentar-se mais flexível no processamento de dados e geração do Mapa Hierárquico de Valor.

Além das limitações do Laddermap, sentiu-se dificuldade na realização das entrevistas, por abordarem questionamentos sobre assuntos não pensados pelos indivíduos, tornando-se cansativas e repetitivas, exigindo-se habilidade do entrevistador em conduzi-las. 


\subsection{Sugestões para futuras pesquisas}

Como sugestão para pesquisas futuras, seria interessante a aplicação da teoria da cadeia de

meios e fins em outros bairros da cidade de Fortaleza (CE), de preferência em bairros nobres, com o intuito de detectar se os valores dominantes para esse público são os mesmos para os bairros mais violentos.

Podem ainda ser desenvolvidas pesquisas quantitativas, envolvendo um número maior de entrevistados, com um questionário estruturado de modo a testar proposições sobre os valores identificados nesta pesquisa.

\section{Referências}

ALVES, Denise Avancini Alves et al. A laddering on-line via chat responde "por que caipirinha? In: ENCONTRO DE MARKETING DA ANPAD, III. Anais... Curitiba: Enanpad, 2008.

DIAS NETO, Theodomiro. Policiamento comunitário e controle sobre a polícia: a experiência norteamericana. São Paulo: IBCCRIM, 2003.

DRUCKER, Peter F. A prática da administração de empresas. São Paulo: Pioneira, 1981.

ENGEL, James F.; BLACKWELL, Roger; MINIARD, Paul W. Comportamento do consumidor. Tradução de Christina Ávila de Menezes. 8. ed. Rio de Janeiro: LTC, 2000.

FIGUEIREDO, Bernardo Amando Batista de. Arte africana: estudo sobre as crenças e preferências de interessados. Dissertação (mestrado em administração) - Pontifícia Universidade Católica do Rio de Janeiro, Rio de Janeiro, 2007.

FLORES NETO, Mario; SILVEIRA, Teniza da. Uma abordagem metodológica mista sobre a cadeia de meios-fins. In: ENCONTRO DA ANPAD, 31., Rio de Janeiro, 2007. Anais... Rio de Janeiro: Anpad, 2007.

GUTMAN, Jonathan. A means end-chain model based on consumer categorization processes. Journal of Marketing, v. 46, n. 2, p. 60-72, Spring 1982.

GUTMAN, Jonathan. Exploring the nature of linkages between consequences and values. Journal of Business Research, New York, v. 22 n. 2, p. 143-148. 1991.

JUCÁ, Roberta Laena Costa. O papel da sociedade na política de segurança pública. Jus Navigandi, Teresina, ano 7, n. 60, nov. 2002. Disponível em: <http://jus2.uol.com.br/doutrina/texto. asp?id=3525>. Acesso em: 19 jul. 2009.

KARSAKLIAN, Eliane. Comportamento do consumidor. São Paulo: Atlas, 2004.

KOTLER, Phillip; HAYERS, Thomas; BLOOM, Paul N. Marketing de serviços profissionais. 2. ed. São Paulo: Manole, 2002. 
KRYSTALLIS, A.; MAGLARAS, G.; MAMALIS, S. Motivations and cognitive structures of consumers in their purchasing of functional foods. Food Quality and Preference, v. 19, p. 525-538, 2008.

NEV/USP. NÚCLEO DE ESTUDOS DA VIOLÊNCIA DA UNIVERSIDADE DE SÃO PAULO. Manual de policiamento comunitário: polícia e comunidade na construção da segurança. São Paulo: NEV/USP, 2009.

PADEL, S.; FOSTER, C. Exploring the gap between attitudes and behaviour: understanding why consumers buy or do not buy organic food. British Food Journal, v. 107, n. 8, p. 606-625, 2005.

PIMENTA, Márcio Lopes; VILAS BOAS, Luiz Henrique de Barros. Percepções de consumidores de alimentos orgânicos na cidade de Uberlândia na perspectiva de valores: uma aplicação da laddering e cadeia de meios e fins. In: ENCONTRO DE MARKETING DA ANPAD, 3., Curitiba, 2008. Anais... Curitiba: EMA, 2008.

PIMENTA, Márcio Lopes. Comportamento do consumidor de alimentos orgânicos na cidade de Uberlândia: um estudo com base na cadeia de meios e fins. Dissertação (mestrado em administração) — Universidade Federal de Uberlândia, Uberlândia, 2008.

REYNOLDS, Thomas J.; GUTMAN, Jonathan. Laddering theory, method, analysis and interpretation. Journal of Advertising Research, New York, v. 28, n. 1. p. 11-31, Feb./Mar. 1988.

REYNOLDS, T.J. et al. A means-end analysis of brand persuasion through advertising. International Journal of Research in Marketing, Amsterdam, v. 12, n. 3, p. 257-266, Sept. 1995.

RONDA do quarteirão: o grande desafio é a unificação com a sustentabilidade. O Povo, 22 set. 2008. Disponível em: <www.opovo.com.br>. Acesso em: 17 jun. 2009.

ROKEACH, Milton, The role of values in public opinion research. California, v. 9, May, 1968.

SCHIFFMAN, Leon G.; KANUK, Leslie Lazar. Comportamento do consumidor. 6. ed. Rio de Janeiro: LTC, 2000.

SCHWARTZ, S.H. Universals in the content and structure of values: theory and empirical tests in 20 countries. Advances in Experimental Social Psychology, New York, v. 25, p. 1-65, 1992.

SCHWARTZ, S.H.; BILSKY, W. Toward a teory of the universal content and structure of values. Journal of Personality and Social Psychology, Washington, v. 53, n. 3, p. 550-562, Sept. 1987.

SCHWARTZ, Shalom H.; SAGIE, Galit. Value consensus and importance: a cross national study. Journal of Cross-Cultural Psychology, v. 31, n. 4, p. 465-497, July 2000.

SECRETARIA DE SEGURANÇA PÚBLICA E DEFESA SOCIAL. O Programa Ronda do Quarteirão. Notícias. Disponível em: <www.sspds.ce.gov.br>. Acesso em: 1ํo dez. 2009.

SENASP. SECRETARIA NACIONAL DE SEGURANÇA PÚBLICA. Curso nacional de promotor de polícia comunitária. Brasília: Senasp, 2007.

SILVEIRA, Teniza da. A gestão do conhecimento sobre valor para o cliente e a performance organizacional. In: ENCONTRO DA ASSOCIAÇÃO NACIONAL DOS PROGRAMAS DE PÓS-GRADUAÇÃO EM ADMINISTRAÇÃO, 27, 2003. Anais... São Paulo: Enanpad, 2003. 
SKOLNICK, Jerome H.; BAYLEY, David H. Policiamento comunitário: questões e práticas através do mundo. Tradução de Ana Luísa Amêndola Pinheiro. São Paulo: Universidade de São Paulo, 2006. (Série Polícia e Sociedade, n. 6)

STUDART, Tulio. O Programa Ronda do Quarteirão. 2009. Palestra realizada na Secretaria de Segurança Pública e Defesa Social do Ceará em 7 maio 2009.

TAMAYO, Alvaro; SCHWARTZ, Shalom H. Estrutura motivacional dos valores humanos. Psicologia: Teoria e Pesquisa, Brasília, v. 9, n. 2, p. 329-348, maio/ago. 1993.

TROJANOWICZ, Robert; BUCQUEROUX, Bonnie. Policiamento comunitário: como começar. Rio de Janeiro: PMERJ, 1994.

VELUDO-DE-OLIVEIRA, Tânia Modesto; IKEDA, Ana Akemi. Valor em serviços educacionais. RAE Eletrônica, v. 5, n. 2, art. 12, jul./dez. 2006.

VILAS BOAS, Luiz Henrique de Barros. Comportamento do consumidor de produtos orgânicos: uma análise na perspectiva da teoria da cadeia de meios e fins. Tese (doutorado em administração) — Universidade Federal de Lavras, Lavras, 2005.

VILAS BOAS, Luiz Henrique de Barros. Perspectivas de segmentação para o mercado de produtos orgânicos com base na estrutura de valores. In: ENCONTRO DA ANPAD, 31., Rio de Janeiro, 2007. Anais... Rio de Janeiro: Anpad, 2007.

VILAS BOAS, Luiz Henrique de Barros et al. Comportamento do consumidor de produtos orgânicos: uma aplicação da teoria da cadeia de meios e fins. In: ENCONTRO DE MARKETING DA ANPAD, 2., 2006. Resumos... Rio de Janeiro: Anpad, 2006.

ZYMAN, Sérgio. O fim do marketing como nós conhecemos. Rio de Janeiro: Campus, 1999.

Liliane Araújo Pinto é professora do Instituto Federal do Piauí (IFPI) - Campus Piripiri. E-mail: lilianepinto@hotmail.com.

Luiz Carlos Murakami é professor da Universidade Federal do Ceará (UFC) - Campus Benfica. E-mail: murakami@ufc.br.

Márcio Lopes Pimenta é professor da Universidade Federal de Uberlândia (UFU). E-mail: pimenta@ fagen.ufu.br.

Natália de Sena Nunes é mestre em administração e controladoria pela UFC. E-mail: nataliasena@gmail.com. 